Article

\title{
An Improved Scheduling Approach for Minimizing Total Energy Consumption and Makespan in a Flexible Job Shop Environment
}

\author{
Zhongwei Zhang ${ }^{1,2}$, Lihui Wu ${ }^{1, *}$, Tao Peng ${ }^{2, *}$ (D) and Shun Jia ${ }^{3}$ \\ 1 School of Mechanical \& Electrical Engineering, Henan University of Technology, Zhengzhou 450001, China; \\ zzw_man@haut.edu.cn \\ 2 State Key Laboratory of Fluid Power and Mechatronic Systems, School of Mechanical Engineering, \\ Zhejiang University, Hangzhou 310027, China \\ 3 Department of Industrial Engineering, Shandong University of Science and Technology, \\ Qingdao 266590, China; jiashun@sdust.edu.cn \\ * Correspondence: wulihui@haut.edu.cn (L.W.); tao_peng@zju.edu.cn (T.P.)
}

Received: 27 November 2018; Accepted: 25 December 2018; Published: 31 December 2018

check for updates

\begin{abstract}
Nowadays, manufacturing industry is under increasing pressure to save energy and reduce emissions, and thereby enhancing the energy efficiency of the machining system (MS) through operational methods on the system-level has attracted more attention. Energy-efficient scheduling (ES) has proved to be a typical measure suitable for all shop types, and an energy-efficient mechanism that a machine can be switched off and back on if it waits for a new job for a relatively long period is another proven effective energy-saving measure. Furthermore, their combination has been fully investigated in a single machine, flow shop and job shop, and the improvement in energy efficiency is significant compared with only applying ES for MS. However, whether such two energy-saving measures can be integrated in a flexible job shop environment is a gap in the existing study. To address this, a scheduling method applying an energy-efficient mechanism is proposed for a flexible job shop environment and the corresponding mathematical model, namely the energy-efficient flexible job shop scheduling (EFJSS) model, considering total production energy consumption (EC) and makespan is formulated. Besides, transportation as well as its impact on EC is taken into account in this model for practical application. Furthermore, a solution approach based on the non-dominated sorting genetic algorithm-II (NSGA-II) is adopted, which can avoid the interference of subjective factors and help select a suitable machine for each operation and undertake rational operation sequencing simultaneously. Moreover, experimental results confirm the validity of the improved energy-efficient scheduling approach in a flexible job shop environment and the effectiveness of the solution.
\end{abstract}

Keywords: machining system; machine; energy consumption; energy-efficient mechanism; energy-efficient flexible job shop scheduling; non-dominated sorting genetic algorithm-II

\section{Introduction}

Manufacturing industry consumes enormous amounts of energy to transform resources into products or services, which increases the competition for energy resources and brings huge pressure to the environment. In China, energy consumed by manufacturing industry takes up nearly $57 \%$ of total national energy consumption (EC) by 2014 [1]. As the countries with the most energy-related $\mathrm{CO}_{2}$ emissions, China and the United States almost account for $40 \%$ of the world's total $\mathrm{CO}_{2}$ emissions, and energy-related $\mathrm{CO}_{2}$ emission accounts for about $80 \%$ of all $\mathrm{CO}_{2}$ emissions in the United States [2]. Thus, it is a huge challenge for manufacturing enterprises to reduce EC and enhance sustainability. 
A machining system (MS), as a typical manufacturing system, usually comprises machine tools, fixtures, cutting tools, workpieces, operators and various machining processes [3]. Since machines are entities implementing various machining processes and the final products are usually directly or indirectly processed by machines, machines are important energy consuming units in MS. Accordingly, reducing the EC of machines has already been proved to be a significant strategy to improve manufacturing sustainability [4]. In general, the energy-saving methods for MS follows two types, namely energy-efficient process planning and energy-efficient scheduling [5]. The former mainly pays attention to the machining EC of machines while the latter aims to minimize non-value added EC in manufacturing process. However, the energy use breakdown in machining processes shows that actual material removal energy is minimal compared with the energy used by auxiliary functions and components of a machine [6]. Furthermore, idle and loss EC take up more than $40 \%$ of total EC [7]. Hence, there is a greater energy-saving potential from the manufacturing system-level perspective. As a workshop can be interpreted as a MS, energy-efficient scheduling (ES) is easier to accept by manufacturing enterprises because it does not substantially change the existing legacy system and requires less investment.

Shop scheduling is a classical decision-making problem, and different scheduling problem types can be categorized by the flowing types of workpiece in the workshop [8]. Owing to the lack of enough attention to the environmental impact of MS in the past, ES research considering EC or environment impact is rather limited and mainly aimed at single machine and flow shop modes. The job shop mode is prevalent in small and medium enterprises, and flexible manufacturing mode is gradually accepted by them for meeting diversified customers' needs and responding to market changes rapidly. Therefore, ES for flexible job shops is worth studying. Besides, traditional job shop scheduling (JSS) and flexible job shop scheduling (FJSS) research usually ignored transportation time. As considering transportation time will make the optimized shop floor schedule more practical, transportation time or the influence of transport resources have already been taken into account in some FJSS research $[9,10]$. Yet, the effects of transportation factors on EC are not involved in these studies. In view of this, considering transportation time, a new general ES model for flexible job shops with two performance criteria, total production EC and makespan, is proposed in this paper.

In the rest of this paper, a literature review on ES for various shop types and the motivation for our research in Section 2 are followed by Section 3 describing the energy-efficient flexible job shop scheduling (EFJSS) problem and the establishment of corresponding model. Details of the application of the non-dominant sorting genetic algorithm-II (NSGA-II) for solving the presented model is illustrated in Section 4, and verifying experiments and results are focused in Section 5. Section 6 presents conclusions and prospects for future research.

\section{Literature Review}

Since machines are key manufacturing resources as well as the main energy sources in a workshop, ES is usually conducted to effectively manage machines from the EC perspective. In general, machine state can be classified into four situations, i.e., start, machining, idle and stop. As ordinary machines are usually operated and controlled manually, the operation time is of great uncertainty. So current energy-efficient MS research mainly addresses numerical control (NC) machines, and the machining EC of a machine can be calculated by the established machining process EC models and further viewed as a constant when the process documents are given [11]. Hence, the EC of machines that current ES research focuses on is different owing to various shop types. As the machining EC of a specific machine often differs when various processing parameters are selected, a small amount of research integrates processing parameter selection to reduce machining EC. By contrast, non-machining EC has drawn significant attention in ES study from the shop-floor level.

Regarding energy-efficient single machine scheduling (SMS), the most valuable achievement is the proposal of energy-efficient mechanism, i.e., switching off the non-bottleneck idle machines if no job needs it [12]. Beyond that, the existing related work mainly focused on the development and/or improvement of dispatching rules, and the influence of different scheduling conditions on 
optimization objectives [12-14]. For instance, as energy prices usually fluctuate, reducing EC can not only reduce $\mathrm{CO}_{2}$ emissions but also save manufacturing costs, especially at the peak period of electricity consumption or high energy price periods.

The main reason for carrying out energy-efficient parallel machine scheduling (PMS) is that the machines with the same manufacturing capability usually hold different energy efficiency. Accordingly, some research considers processing parameter setting simultaneously. Fang et al. [15] investigated minimizing the weighted sum of tardiness penalty and power consumption cost by considering a higher cutting speed may enhance the productivity at the cost of more EC. Similarly, in view of the fact that a higher cutting speed may incur high power load peaks, Wang et al. [16] examined the PMS problem with flexible resources and a bounded power demand peak.

Regarding energy-efficient flow shop scheduling (FSS) and the extension of it, different mixed integer programming models considering EC and EC-related objectives (e.g., peak power, power cost and carbon footprint) had been proposed under various conditions in the existing study [17-21]. Typically, Luo et al. [18] studied a hybrid FSS problem with the continuous change of electricity price; in [20], not only the energy-efficient mechanism proposed in energy-efficient SMS research was introduced into an energy-efficient flexible flow shop scheduling (FFSS) model but also spindle speed selection was integrated; Wu et al. [21] established a FFSS model considering the periodicity and the limited storage capacity of renewable energy.

Regarding ES for a job shop, as each job has a fixed process route, total job-related processing EC can be viewed as a constant and black box, and total idle EC attracts the most attention [22]. As for a flexible job shop, although it is the extension of the job shop, the EC concerned is different. Since the task-driven EC is greatly influenced by the variability and flexibility of task flow [23], EC can be optimized by selecting suitable machines for jobs and arranging appropriate processing sequences in flexible job shops [11]. Correspondingly, total production EC, including total processing EC and idle $\mathrm{EC}$, or total environmental impact according to the conversion relationship between energy and $\mathrm{CO}_{2}$ emissions, can be optimized [24].

To summarize, ES research considering objectives related to environmental influence is increasing but limited. Current study mostly focuses on SMS and FSS, and other shop types are seldom touched, especially flexible job shop. However, the effectiveness of several typical energy-saving methods stated in the aforementioned research has been verified, including operation sequencing, switching off the idle machine and then switching on it before the arrival of new job (i.e., an energy-efficient mechanism), process route selection, and machining parameter selection. Among them, process route selection is not applicable for workshops in which each job has a fixed process route (e.g., classical job shop) and machining parameter selection is only suitable for the condition that an operation has alternative machining parameters. Moreover, EC calculation is the basis of EC optimization, resulting in the application effect of the optimized scheduling schemes depending largely on the accuracy and reliability of energy models or data of machines. Nevertheless, the real and reliable energy-related data provided in the existing ES cases is rather limited, leading to enormous difficulty in evaluating the energy-saving effect objectively. In contrast, more focus is on the algorithms for solving scheduling problems, especially modern intelligent algorithms, such as genetic algorithm (GA), particle swarm optimization (PSO) algorithm, Simulated annealing (SA) algorithm and the hybrid algorithm based on them. Therefore, how to reduce EC through operational approaches has not been well investigated for a typical flexible job shop environment, and a relatively general EFJSS model needs addressing to facilitate the follow-up research with more sophisticate situations, e.g., machine failure, workload constrains or recirculation. In addition, although some research had already been carried out on the combination of energy-efficient mechanism with energy-efficient SMS, FFSS, and JSS [12,20,22], how to apply energy-efficient mechanism to an EFJSS environment is a gap in the existing study, which deserves exploring. 


\section{Energy-Efficient Flexible Job Shop Scheduling Model}

Based on previous studies, manufacturing EC is tried to be reduced by ES combined with energy-efficient mechanism in flexible job shops. Correspondingly, EC and makespan, reflecting production efficiency, are chosen as two optimization objectives.

\subsection{Energy-Efficient Mechanism}

When a machine is turned on, there is a start-up order among different power supply modules (e.g., power supply for electricity box, main power supply, and power supply for NC system). The power off sequences are usually in the opposite order of the start-up. As these operations are usually regulated in machine manual, the corresponding EC for a specific machine can be measured or calculated, then viewed as a constant value. Hence, if the influence of warm-up operation after starting up on machining quality is ignored, energy will be saved by switching the idle machine off and then switching it on before a new job arrives. Such a turn-off and then turn-on operation sequence was defined as a "Setup" operation in [12], and this definition is adopted in our study. Accordingly, energy-efficient mechanism is the execution of Setup operation, as is displayed by Figure 1.

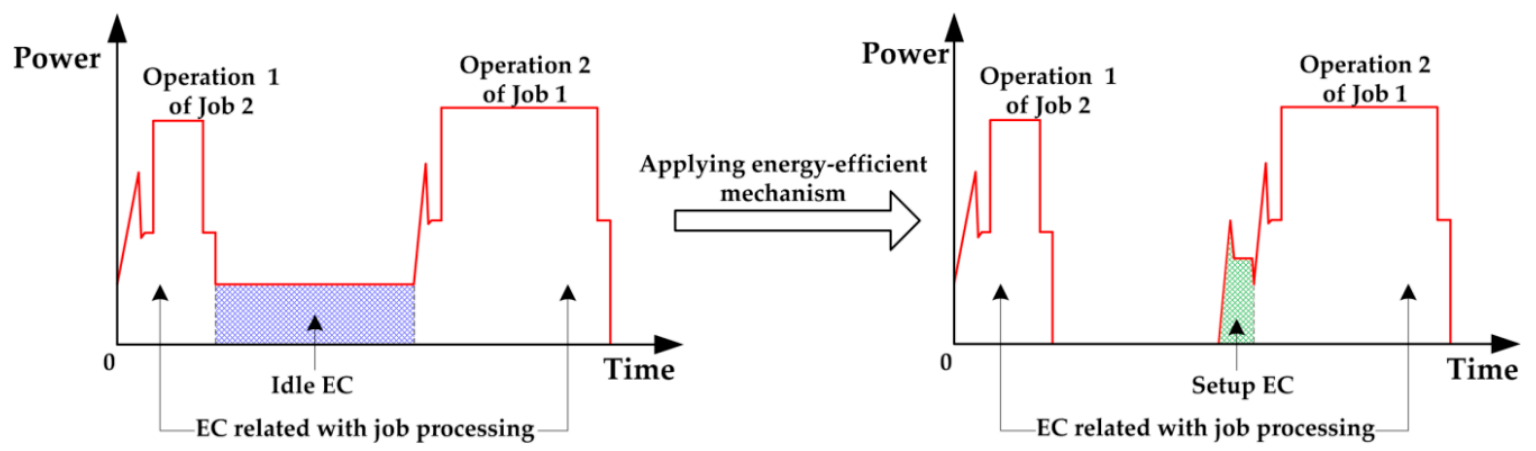

Figure 1. The schematic diagram of the energy-efficient mechanism.

When putting this energy-efficient mechanism in practical use, it is essential to judge whether the idle machines should be off. Based on previous analysis, a Setup operation takes at least a predefined amount of time ( $\left.T_{\text {Setup }}\right)$, so the corresponding EC ( $\left.E_{\text {Setup }}\right)$ can be viewed as constant for a specific machine. Suppose $T_{\text {idle }}$ is the inter-arrival time between jobs, since the idle power of a machine $\left(P^{\mathrm{SO}}\right)$ is usually stable, the idle EC is the product of $P^{\mathrm{SO}}$ and $T_{\text {idle. }}$ Obviously, when $T_{\text {idle }} \geq T_{\text {Setup }}$ and $P^{S O} T_{\text {idle }} \geq E_{\text {Setup }}$ are both satisfied, amounts of energy can be saved as Setup operations can be executed during the idle periods. Let $T_{\mathrm{B}}$ be the break-event duration, i.e., the least time required for a Setup operation, it can be calculated by:

$$
T_{\mathrm{B}}=\frac{E_{\text {Setup }}}{P^{\mathrm{SO}}}
$$

Accordingly, if $T_{\text {idle }} \geq \max \left(T_{\mathrm{B}}, T_{\text {Setup }}\right)$, the idle machine can perform Setup operation.

\subsection{Problem Statement and Model Hypothesis}

FJSS is further developed from classical JSS. To obtain feasible scheduling schemes, two subordinate issues, i.e., machine selection and operation sequencing, needs tackling. Moreover, as EC is an environment-related objective, it is vital to evaluate it when modeling a FJSS problem.

Although a MS contains various technical equipments and consumes different types of energy and media (e.g., electricity, diesel and cooling water), we only pay attention to the direct EC of NC machines in the whole manufacturing process, and the indirect EC [25] as well as the embodied EC [26] of auxiliary materials is ignored in order to simplify study and facilitate result comparison. Based on current research, some other assumptions made for modeling EFJSS are listed below. 
(1) Jobs are mutually independent and there is no priority difference for them.

(2) Each machine cannot process more than one job at a time, and job pre-emption or cancellation is forbidden once processing starts.

(3) Each job contains sequential operations, and each operation can only be executed on one machine in actual production. When an operation of a job, not the terminal operation, ends, such a job is immediately transported to the machine arranged for its next operation, i.e., without regard for batch transportation.

(4) Transportation time varies with the different machines selected for pre- and post-operation of a job, and it is only related to transportation distance. In particular, transportation time is considered as zero under the condition that a machine processes two adjacent operations of a job.

(5) Input buffer of each machine is unlimited. The initial position of each job is the machine executing its first operation, and the ending position is the machine performing its last operation, i.e., transportation is not needed for the first and the last operations of each job.

(6) The processing time of an operation is composed of machining time and auxiliary time (e.g., clamping, inspection and cleaning times).

(7) Each operation on the selected NC machine is executed according to the fixed NC programs.

(8) All jobs are simultaneously available at time zero, and breakdown is not considered.

(9) Total production EC is evaluated with makespan as time boundary.

(10) The energy-efficient mechanism is adopted, and the warm-up operation is neglected.

\subsection{Mathematical Model}

A typical EFJSS problem contains $m$ machines and $n$ jobs. Each job $i(i=1,2, \ldots, n)$ comprises a sequence of operation $O_{i j}, j=1,2, \ldots, J_{i}$, where $J_{i}$ represents the total number of operations in job $i$. All operations that can be executed on machine $k(k=1,2, \ldots, m)$ form a set $N_{k}$, and each operation $O_{i j}$ in $N_{k}$ has a corresponding processing time and EC, denoted as $T P_{i j k}$ and $M E_{i j k}$ respectively. According to the Therblig-based energy supply models of machines, the idle power of machine $k$ can be identified by its Therblig-SO power, namely $P_{k}^{S O}$. The Setup operation time and the corresponding EC of machine $k$ is denoted as $T_{k}^{\text {Setup }}$ and $E_{k}^{\text {Setup }}$ respectively. $T R T_{k q}$ is the transportation time from machine $q(q=1,2, \ldots, m)$ to machine $k$. $H$ is an extremely large positive number. In addition, some decision variables, namely $S_{i j}, C_{i j}, X_{i j k}$ and $Y_{i j i^{*} j^{*} k}$, are denoted, where $S_{i j}$ and $C_{i j}$ indicate the initial and terminal time of $O_{i j}$ respectively, $X_{i j k}$ is an integer variable whose value is 1 if machine $k$ executes $O_{i j}$ and 0 otherwise, and $Y_{i j i^{*} j^{*} k}$ is also an integer variable with value 1 if $O_{i j}$ is processed before $O_{i^{*} j^{*}}$ when they are both executed on machine $k$ and 0 otherwise.

As the time boundary for analyzing EC, the makespan of all jobs ( $\left.T_{\text {makespan }}\right)$ can be obtained by:

$$
T_{\text {makespan }}=\max \left\{C_{i j}\right\}, \forall i, j
$$

Consequently, the total production EC ( $\left.E_{\text {total }}\right)$ is the sum of the EC of all machines related with jobs, which can be expressed below:

$$
E_{\text {total }}=\sum_{k=1}^{m}\left(E I_{k}+E M_{k}\right)
$$

where $E I_{k}$ is the sum of EC during all standby periods of machine $k$ and $E M_{k}$ is the total processing EC, which can be further presented below:

$$
E M_{k}=\sum_{\left\{(i, j): O_{i j} \in N_{k}\right\}} M E_{i j k} X_{i j k}, \forall k
$$


As for $E I_{k}$, when all machines are not allowed to be turned off during idle time, it can be expressed as:

$$
E I_{k}=P_{k}^{\mathrm{SO}}\left[\max _{\left\{(i, j): O_{i j} \in N_{k}\right\}}\left\{C_{i j}\right\}-\min _{\left\{(i, j): O_{i j} \in N_{k}\right\}}\left\{S_{i j}\right\}-\sum_{\left\{(i, j): O_{i j} \in N_{k}\right\}} T P_{i j k} X_{i j k}\right], \forall k
$$

For a given scheduling scheme, the machine distribution for each operation is determined. Let $R_{k}$ be the actual number of operations executed on machine $k$, which can be calculated by:

$$
R_{k}=\sum_{\left\{(i, j): O_{i j} \in N_{k}\right\}} X_{i j k}, \forall k
$$

Obviously, if there are $R_{k}$ operations processed on machine $k, R_{k}-1$ idle intervals between adjacent operations will exist at most. Suppose $O_{i j}$ is the $l$ th $\left(1 \leq l \leq R_{k}-1\right)$ operation performed on machine $k$, $O_{i^{\prime} j^{\prime}}$ is its adjacent subsequent operation on machine $k$, and the parameters, namely $S_{i j}, C_{i j}, S_{i^{\prime} j^{\prime}}$ and $C_{i^{\prime} j^{\prime}}$, are remarked as $S_{i j}^{l k}, C_{i j}^{l k}, S_{i^{\prime} j^{\prime}}^{(++1) k}$ and $C_{i^{\prime} j^{\prime}}^{(l+1) k}$ respectively, the EC of each idle interval on machine $k$ when applying an energy-efficient mechanism can be expressed as follows:

$$
\begin{aligned}
& E I_{k}^{l}= \begin{cases}E_{k}^{\text {Setup }} & \text { if } P_{k}^{\mathrm{SO}}\left(S_{i^{\prime} j^{\prime}}^{(l+1) k}-C_{i j}^{l k}\right)>E_{k}^{\text {Setup }} \text { and }\left(S_{i^{\prime} j^{\prime}}^{(l+1) k}-C_{i j}^{l k}\right)>T_{k}^{\text {Setup }}, \\
P_{k}^{\mathrm{SO}}\left(S_{i^{\prime} j^{\prime}}^{(l+1) k}-C_{i j}^{l k}\right) & \text { otherwise }\end{cases} \\
& \forall k,(i, j),\left(i^{\prime}, j^{\prime}\right): O_{i j} \in N_{k}, O_{i^{\prime} j^{\prime}} \in N_{k}, X_{i j k}=1, X_{i^{\prime} j^{\prime} k}=1, Y_{i j i^{\prime} j^{\prime} k}=1 ; l=1,2, \ldots, R_{k}-1
\end{aligned}
$$

Then, $E I_{k}$ can be presented below:

$$
E I_{k}=\sum_{l=1}^{R_{k}-1} E I_{k}^{l}
$$

According to Formulae (5)-(7), no matter whether the energy-efficient mechanism is applied, $E I_{k}$ is mainly determined by the decision variable $S_{i j}, C_{i j}$ and $X_{i j k}$. Combined with Formula (4), it can be known that the EC calculation is closely related to the values of decision variables. So it is essential to acquire the values of all decision variables firstly to further calculate EC. The optimization objectives are presented below:

$$
\left\{\begin{array}{l}
\text { Minimize }\left[T_{\text {makespan }}\right] \\
\text { Minimize }\left[E_{\text {total }}\right]
\end{array}\right.
$$

subject to:

$$
\begin{gathered}
\sum_{k: O_{i j} \in N_{k}} X_{i j k}=1, \\
C_{i j}=S_{i j}+\sum_{\left\{k: O_{i j} \in N_{k}\right\}} T P_{i j k} X_{i j k}, \forall i, j \\
C_{i j}-C_{i^{*} j^{*}}+H\left(1-X_{i j k}\right)+H\left(1-X_{i^{*} j^{*} k}\right)+H Y_{i j^{*} j^{*} k} \geq T P_{i j k}, \forall k,(i, j),\left(i^{*}, j^{*}\right): O_{i j}, O_{i^{*} j^{*}} \in N_{k} \\
C_{i^{*} j^{*}}-C_{i j}+H\left(1-X_{i j k}\right)+H\left(1-X_{i^{*} j^{*} k}\right)+H\left(1-Y_{i j^{*} *^{*} k}\right) \geq T P_{i^{*} j^{*} k}, \forall k,(i, j),\left(i^{*}, j^{*}\right): O_{i j}, O_{i^{*} j^{*}} \in N_{k} \\
H\left(1-X_{i j k}\right)+H\left(1-X_{i(j-1) q}\right)+S_{i j}-C_{i(j-1)} \geq T R T_{k q}, \forall k, q, i, j=2, \ldots, J_{i}: O_{i j} \in N_{k}, O_{i(j-1)} \in N_{q} \\
S_{i j} \geq 0, \forall i, j
\end{gathered}
$$

Constraint (10) represents that each operation is not allowed to be executed on more than one machine anytime. Constraint (11) notes that machine selection affects the earliest finish time of an operation, and the processing cannot be interrupted until it is finished. Constraints (12) and (13) are to guarantee that two operations belonging to various jobs cannot be executed simultaneously when both are arranged on the same machine. Constraint (14) states that precedence relationships cannot 
be violated and transportation affects the initial time of each operation. Constraint (15) ensures that the initial time of each operation is non-negative. Furthermore, it can be concluded that the allowable earliest initial time of an operation is constrained by transportation and manufacturing resource from Constraints (12)-(14), and such an impact relationship can be depicted by Figure 2.

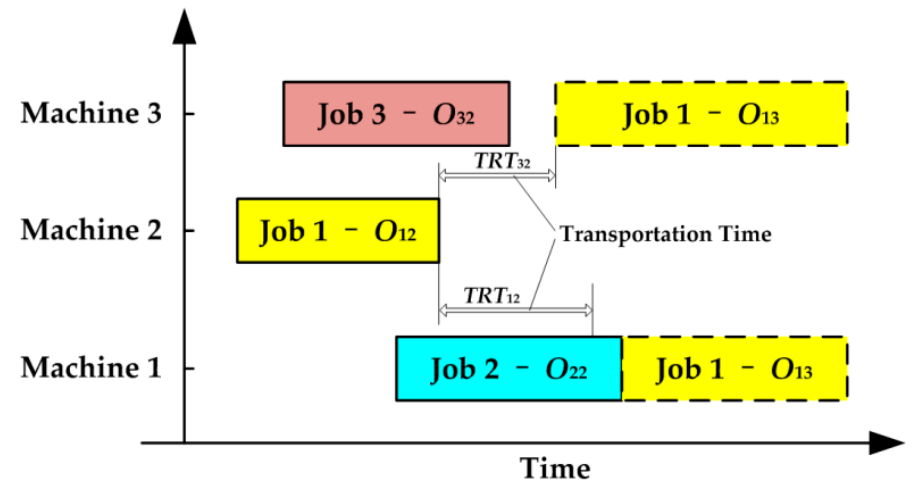

Figure 2. Constraints of transportation time and equipment resources on the starting time of an operation.

When calculating $E_{\text {total }}$, the input parameters, namely $T P_{i j k}, M E_{i j k}, P_{k}^{S O}, T_{k}^{\text {setup }}, E_{k}^{\text {setup }}$ and $T R T_{k q}$, should be obtained in advance. The processing time of an operation $\left(T P_{i j k}\right)$ consists of machining time and necessary auxiliary time based on a research assumption. Since the NC program contains the information of cutting tool path and processing parameters, machining time can be obtained by analyzing the NC program [27]. Besides, in order to make reasonable production plans and analyze production efficiency, the standard labor time or man-hour quota is commonly applied in manufacturing enterprises. Correspondingly, the auxiliary time of each operation can be viewed as a constant. Except process time analysis, the EC models of related machines also need to be established beforehand. Although a multitude of research has been carried out on EC modeling for machines and various models has been put forward, the Therblig-based model $[28,29]$ is adopted here in view of accuracy and applicability. Furthermore, $M E_{i j k}$ can be calculated by combining the analysis of processing time with the already Therblig power models of machines, including Therblig-SO power $\left(P_{k}^{\mathrm{SO}}\right)$. In addition, the Setup operation time $\left(T_{k}^{\text {setup }}\right)$ can also be obtained by the methods of making standard labor time, and the corresponding EC $\left(E_{k}^{\text {setup }}\right)$ can be measured with EC collection equipment. Moreover, due to the relatively fixed workshop layout and the assumption that transportation time is only related to transportation distance, the transportation time between various machines $\left(T R T_{k q}\right)$ can be set by a man-hour quota system or obtained through simulation with some digital plant simulation softwares (e.g., Delmia Quest and Tecnomatix).

\section{Model Solution Based on Non-Dominated Sorting Genetic Algorithm-II(NSGA-II)}

FJSS is NP-hard and it is formidable to obtain the exact optimal solutions for large scale problems in finite time. Hence, modern intelligent algorithms, e.g., ant colony optimization (ACO) algorithm, GA, PSO and SA, are gradually prevalent, and have been utilized for seeking the near-optimal solutions of a FJSS problem in reasonable time [30,31]. Furthermore, the established EFJSS model is a multi-objective function with constraints. Obviously, the solution of it is actually solving a multi-objective optimization problem (MOP). However, it is impossible to make all independent and conflicting objectives optimal simultaneously. Traditional basic idea for solving an MOP is transforming it to a single-objective optimization problem (SOP), and the typical methods include the weighted sum, goal programming and min-max algorithm [32,33]. However, the solution of a MOP is usually not unique. In view of the advantages of the intelligent optimization algorithm, namely high parallelism, self-organization, self-learning and self adaptation, the NSGA-II originated from GA is utilized to acquire the Pareto set of the proposed EFJSS model. The general flow chart of NSGA-II is shown by Figure 3, and more details can be known from [34]. 


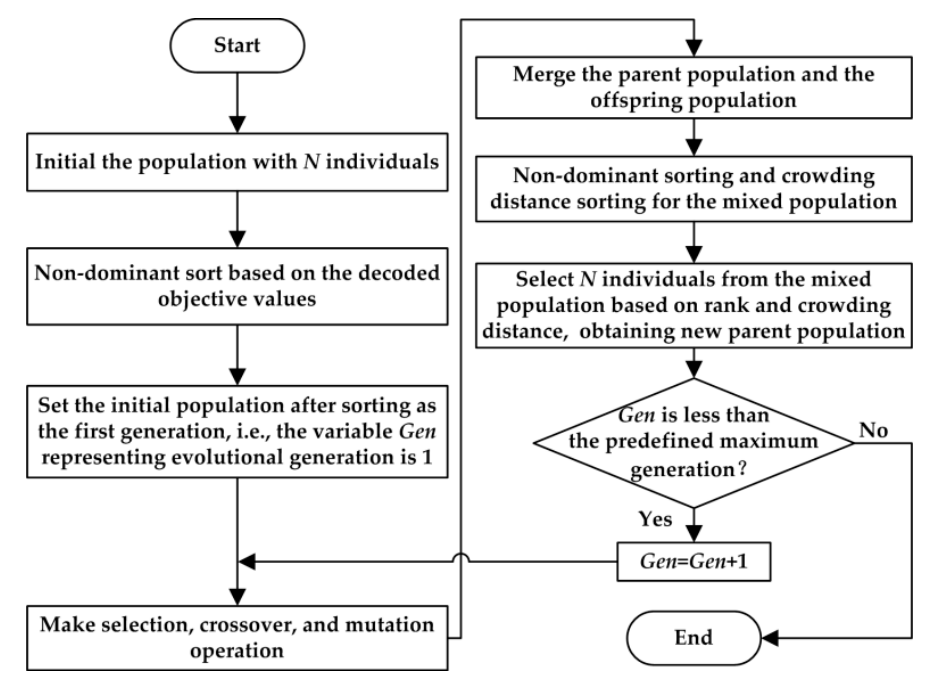

Figure 3. The flow chart of the non-dominated sorting genetic algorithm-II(NSGA-II)

\subsection{Encoding Scheme}

FJSS need address two core issues: machine selection and operation sequencing. Correspondingly, the chromosome should contain the information related to machines and operation sequences, and the operation-based encoding schema can be adopted. Each gene in a chromosome representing an operation is coded as the form $(i, k)$. The $j$ th gene like $(i, k)$ stands for $O_{i j}$ executed on machine $k$. Moreover, the genes related to job $i$ should appear $J_{i}$ times, and they are located in the chromosome randomly while satisfying order constraints. Therefore, the chromosome length of each individual representing a solution is $\sum_{i=1}^{n} J_{i}$.

\subsection{Decoding Scheme}

The evaluation of each objective relies on the values of decision variables when all input parameters are known. Correspondingly, chromosome decoding is mainly to determine the values of decision variables which actually reflect the machine selection and time information of each job, obtaining feasible schedule and the values of optimization objectives. According to research hypotheses, there are three possible schedule types, namely semi-active schedule, active schedule and non-delay schedule [35]. In order to reduce total production EC as much as possible while shortening makespan, the active schedule is adopted in our study, and a decoding method based on [36] is presented to acquire feasible active schedule and the corresponding values of other decision variables. Suppose $A S_{i j}$ is the allowable earliest starting time of $O_{i j}$, the decoding details for any given chromosome are expressed below:

Step 1 Acquire the values of $X_{i j k}$ and $Y_{i j i^{*} j^{*} k}$ by Constraint (10) and the encoding schema.

Analyze the genes successively, and determine the value of $S_{i j}$. For the gene $(i, k)$ representing $O_{i j}, A S_{i j}$ is non-negative, and $A S_{i j}=C_{i(j-1)}+T R T_{k q}$ based on Constraints (14) and (15), $\forall i, j=2,3, \ldots, J_{i}, k$, $q: O_{i j} \in N_{k}, O_{i(j-1)} \in N_{q}$. Check the operations performed on machine $k$ that have already been

Step 2 analyzed and obtain all idle ranges [IT_S, IT_E]. Then, check each idle interval [IT_S, IT_E] successively, if $\max \left\{A S_{i j}, I T \_S\right\}+T P_{i j k} \leq I T \_E, S_{i j}=I T \_S$ and the value of related $Y_{i j i^{*} j^{*} k}$ should be changed according to new order; otherwise, check next idle range. When $O_{i j}$ cannot be inserted into any idle range, $S_{i j}$ will take the maximum of $A S_{i j}$ and the end time of the immediate predecessor of $O_{i j}$ on machine $k$ according to Constraint (12) along with (13).

Step 3 Determine the value of $C_{i j}$. According to Constraint (11), $C_{i j}=S_{i j}+T P_{i j k}$. If the genetic analysis is not finished, turn to Step 2.

Step 4 Combined with the obtained values of decision variables, $T_{\text {makespan }}$ can be determined by Formula (2) and $E_{\text {total }}$ can be calculated by Formulae (3) and (4), (6)-(8). 


\subsection{Initial Population}

Based on the encoding schema, a set including all values of job layer can be obtained firstly, i.e., there are $J_{i}$ elements equal to $i$, and the number of all elements in such set is $\sum_{i=1}^{n} J_{i}$. Then, owing to the fixed chromosome length (i.e., $\sum_{i=1}^{n} J_{i}$ ), all elements will be randomly assigned to the job layer of each gene in the chromosome. Correspondingly, the operation represented by each gene can be acquired. Finally, assign a machine to each operation from its optional machine set randomly, acquiring the value of the corresponding gene's machine layer.

\subsection{Non-Dominated Sorting}

All feasible solutions can be represented by different individuals of the population, and they can be ranked in various Pareto fronts through non-dominated sorting. The objective functions shown by Formulae (2) and (3) are used to evaluate the dominance relationship between different individuals, then determining the fronts as well as its containing elements. Correspondingly, the individuals belonging to higher front set are preferable. The commonly-used method for non-dominated sorting is fast sort algorithm, which had been fully illustrated in [34].

\subsection{Crowding Distance Sorting}

The introduction of crowding distance is to assess the Euclidian distance between individuals belonging to the same front according to their objective values. Accordingly, crowding distance sorting can guarantee the diversity of population, which is similar to genetic mutation operation. Note that crowding distance comparison is meaningless for individuals with various Pareto ranks. Generally, the crowding distance for an individual locating between two boundaries of the front is the sum of the normalized distance between its adjacent neighbors based on each objective function. In particular, the crowding distances for individuals distributed in the boundary are set to infinity.

\subsection{Genetic Operators}

Selection is carried out based on tournament selection here. Firstly, select a certain number of individuals from the current generation randomly. Then, make non-dominated sorting and crowding distance sorting based on the decoded objective function values. The individual locating in a higher front as well as having the largest crowding distance will be selected to form a mating pool, whose size is usually set as half of the population size. Such operations will be repeated until the mating pool is full, and the following crossover and mutation operations will be carried out based on the individuals in mating pool.

Regarding crossover operation, a single-point crossover operator is applied. The detailed procedures and a crossover example for $3 \times 3$ flexible job shop are shown by Figure 4 .

Then the swap mutation operator, i.e., exchanging two different arbitrary genes of the chromosome, is employed for a mutation operation. In particular, if such two genes having the same value on job layer, the chromosome obtained after mutation operation may be illegal, as each gene represents an operation and the contents of each operation's alternative machine set are usually various. Hence, it is necessary to further examine the values of machine layer for two swapped genes in this condition. If the machine selected cannot execute an operation, choose a machine from its alternative machine set randomly, then update the value of machine layer for the corresponding gene. 


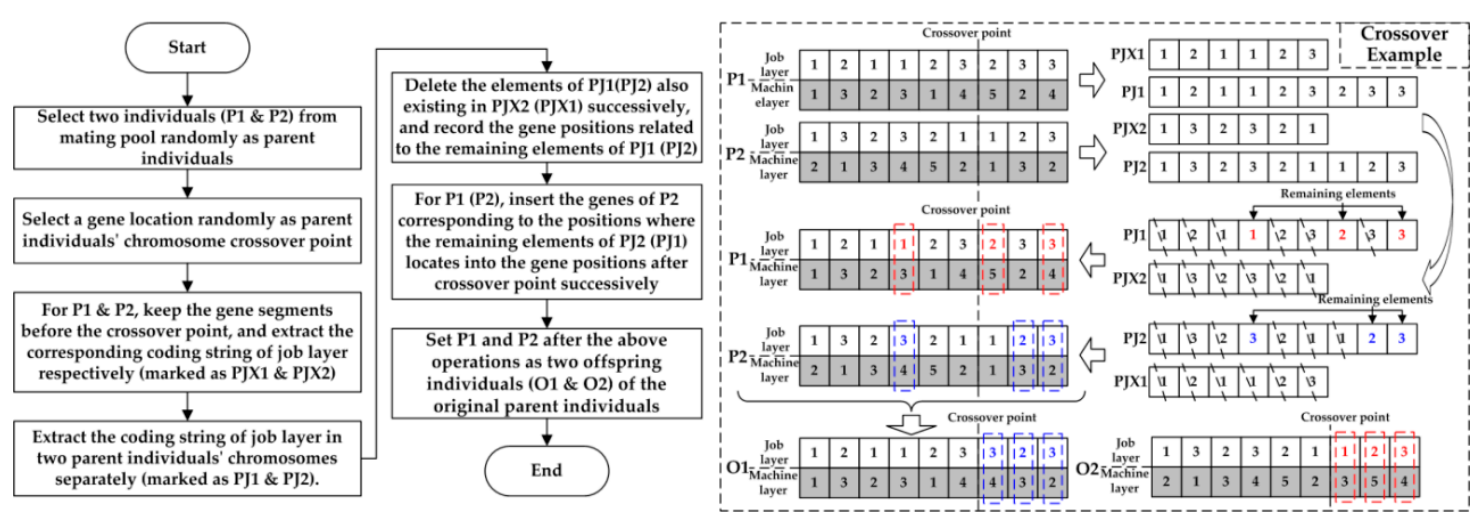

Figure 4. Single-point crossover operation and an example.

\section{Experiments}

To evaluate the relationship of two criteria in flexible job shops, apply the proposed improved scheduling approach and verify the effectiveness of NSGA-II in solving a EFJSS problem, two experiments were conducted respectively.

\subsection{Experiment 1}

Owing to the lack of FJSS examples with reliable EC data in the current study, this experiment was carried out based on the example in our early study [37], and the EC data needed was further enriched. Such an example was composed of five machines and seven independent jobs corresponding to three sorts of parts, as shown in Figure 5. Moreover, the established Therblig power models of each machine, the detailed process plan of each job, as well as the EC calculation for each operation can also be referred to. Some important information, including $T P_{i j k}$ and $M E_{i j k}$, is briefly shown in Table 1 . Additionally, to determine $E_{k}^{\text {setup }}$ and $T_{k}^{\text {setup }}$, the experimental setup used for Therblig power modeling can still be applied according to the standard operation specification of each machine, and an example is displayed in Figure 6. The Setup operation was carried out by skilled workers three times for each machine, and the mean values of the measured EC and time were set as $E_{k}^{\text {setup }}$ and $T_{k}^{\text {setup }}$ respectively, as expressed in Table 2. Besides, the virtual environment of manufacturing workshop was established with Delmia Quest. All workpieces were transported by handcart, then the average transportation time between different machine tools (i.e., $T R T_{k q}$ ) can be obtained through logistic simulation analysis, as shown in Table 3.

Then, the relationship between EC and makespan was analyzed in four working modes. The former two modes were corresponding to EFJSS while the rest two modes were corresponding to energy-efficient job shop scheduling (EJSS). However, the difference existing in the former two modes as well as the latter two ones were the same, i.e., whether the energy-efficient mechanism was applied. Specifically, an energy-efficient mechanism was utilized in modes 1 and 3 . Note that the arrangements in mode 3 and 4 shown by Table 4 was mainly for the balanced use of machines.

After all input parameters needed for evaluating $E_{\text {total }}$ were determined, the NSGA-II was implemented in Matlab language on a PC with Intel Core(TM) i5-6500 3.20GHz CPU, 8GB RAM, and Windows 7. The basic parameters for NSGA-II are listed in Table 5. Then, the algorithm was run 15times respectively to obtain the Pareto front corresponding to various working modes. Comparison of solutions in four working modes is shown by Figure 7. Specifically, schedule Gantt charts corresponding to the solutions in two boundaries of the Pareto front in working mode 1 are depicted by Figure 8 . 
Table 1. Processing time and energy consumption (EC) of each operation [37].

\begin{tabular}{|c|c|c|c|c|c|c|c|c|}
\hline Part & Job & Operation & Machine & $\begin{array}{c}1 \\
\text { (CK6136i) }\end{array}$ & $\begin{array}{c}2 \\
\text { (CK6153i) }\end{array}$ & $\begin{array}{c}3 \\
\text { (CAK6150Di) }\end{array}$ & $\begin{array}{c}4 \\
\text { (JTVM6540) }\end{array}$ & $\begin{array}{c}5 \\
\text { (XHK-714F) }\end{array}$ \\
\hline \multirow{3}{*}{ A } & \multirow{3}{*}{$1-3$} & & 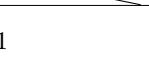 & $\begin{array}{c}89 \mathrm{~s} \\
1.0684 \times 10^{5} \mathrm{~J}\end{array}$ & $\begin{array}{c}89 \mathrm{~s} \\
1.2173 \times 10^{5} \mathrm{~J}\end{array}$ & $\begin{array}{c}89 \mathrm{~s} \\
1.2599 \times 10^{5} \mathrm{~J}\end{array}$ & - & 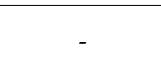 \\
\hline & & & 2 & $\begin{array}{c}84 \mathrm{~s}, \\
0.8870 \times 10^{5} \mathrm{~J}\end{array}$ & $\begin{array}{c}84 \mathrm{~s}, \\
1.0206 \times 10^{5} \mathrm{~J}\end{array}$ & $\begin{array}{c}84 \mathrm{~s}, \\
1.0615 \times 10^{5} \mathrm{~J}\end{array}$ & - & - \\
\hline & & & 3 & - & - & - & $\begin{array}{c}67 \mathrm{~s}, \\
4.7815 \times 10^{4} \mathrm{~J}\end{array}$ & $\begin{array}{c}66 \mathrm{~s}, \\
4.7912 \times 10^{4} \mathrm{~J}\end{array}$ \\
\hline \multirow{4}{*}{ B } & \multirow{4}{*}{4,5} & & 1 & - & - & - & $\begin{array}{c}996 \mathrm{~s} \\
1.0986 \times 10^{6} \mathrm{~J}\end{array}$ & $\begin{array}{c}956 \mathrm{~s} \\
1.1109 \times 10^{6} \mathrm{~J}\end{array}$ \\
\hline & & & 2 & - & - & - & $\begin{array}{c}532 \mathrm{~s} \\
5.3333 \times 10^{5} \mathrm{~J}\end{array}$ & $\begin{array}{c}525 \mathrm{~s} \\
5.4448 \times 10^{5} \mathrm{~J}\end{array}$ \\
\hline & & & 3 & - & - & - & $\begin{array}{c}85 \mathrm{~s}, \\
5.1481 \times 10^{4} \mathrm{~J}\end{array}$ & 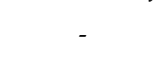 \\
\hline & & & 4 & - & - & - & $\begin{array}{c}155 \mathrm{~s} \\
1.1115 \times 10^{5} \mathrm{~J}\end{array}$ & $\begin{array}{c}133 \mathrm{~s}, \\
9.9921 \times 10^{4} \mathrm{~J}\end{array}$ \\
\hline \multirow{2}{*}{ C } & \multirow{2}{*}{6,7} & & 1 & - & - & - & $\begin{array}{c}229 \mathrm{~s} \\
2.4488 \times 10^{5} \mathrm{~J}\end{array}$ & $\begin{array}{c}226 \mathrm{~s} \\
2.6095 \times 10^{5} \mathrm{~J}\end{array}$ \\
\hline & & & 2 & - & - & - & $\begin{array}{c}508 \mathrm{~s}, \\
5.1276 \times 10^{5} \mathrm{~J}\end{array}$ & $\begin{array}{c}493 \mathrm{~s} \\
4.8041 \times 10^{5} \mathrm{~J}\end{array}$ \\
\hline
\end{tabular}

Table 2. Average Setup operation time and EC of each machine.

\begin{tabular}{ccccc}
\hline Machine & $\boldsymbol{k}$ & $\boldsymbol{E}_{\boldsymbol{k}}^{\text {Setup }}[\mathbf{J}]$ & $\boldsymbol{T}_{\boldsymbol{k}}^{\text {Setup }}[\mathbf{s}]$ & $\boldsymbol{P}_{\boldsymbol{k}}^{\text {SO }}[\mathbf{W}]$ \\
\hline CK6136i & 1 & $1.9065 \times 10^{4}$ & 60 & 335.7 \\
CK6153i & 2 & $2.7800 \times 10^{4}$ & 75 & 332.1 \\
CAK6150Di & 3 & $2.8400 \times 10^{4}$ & 80 & 414.0 \\
JTVM6540 & 4 & $2.7000 \times 10^{4}$ & 65 & 360.5 \\
XHK-714F & 5 & $2.9700 \times 10^{4}$ & 75 & 371.0 \\
\hline
\end{tabular}

Table 3. Average transportation time of workpieces between different machines.

\begin{tabular}{cccccc}
\hline Tnitial Position & CK6136i & CK6153i & CAK6150Di & JTVM6540 & XHK-714F \\
\cline { 1 - 4 } CK6136i & 0 & $150 \mathrm{~s}$ & $210 \mathrm{~s}$ & $465 \mathrm{~s}$ & $515 \mathrm{~s}$ \\
CK6153i & $180 \mathrm{~s}$ & 0 & $250 \mathrm{~s}$ & $450 \mathrm{~s}$ & $475 \mathrm{~s}$ \\
CAK6150Di & $220 \mathrm{~s}$ & $270 \mathrm{~s}$ & 0 & $435 \mathrm{~s}$ & $425 \mathrm{~s}$ \\
JTVM6540 & $485 \mathrm{~s}$ & $460 \mathrm{~s}$ & $500 \mathrm{~s}$ & 0 & $535 \mathrm{~s}$ \\
XHK-714F & $530 \mathrm{~s}$ & $510 \mathrm{~s}$ & $520 \mathrm{~s}$ & $505 \mathrm{~s}$ & 0 \\
\hline
\end{tabular}

Table 4. Machine selection for each job in working mode 3 and 4.

\begin{tabular}{cccccc}
\hline Job & Operation & $\mathbf{1}$ & $\mathbf{2}$ & $\mathbf{3}$ & $\mathbf{4}$ \\
\hline & 1 & CK6136i & CK6153i & JTVM6540 & - \\
& 2 & CK6153i & CAK6150Di & XHK-714F & - \\
& 3 & CAK6150Di & CK6136i & JTVM6540 & - \\
& 4 & JTVM6540 & XHK-714F & JTVM6540 & JTVM6540 \\
& XHK-714F & JTVM6540 & JTVM6540 & XHK-714F \\
& JTVM6540 & XHK-714F & - & - \\
& XHK-714F & JTVM6540 & - & - \\
\hline
\end{tabular}

Table 5. Parameter setting of NSGA-II.

\begin{tabular}{cccccc}
\hline Parameter & $\begin{array}{c}\text { Population } \\
\text { Size }\end{array}$ & $\begin{array}{c}\text { Evolutional } \\
\text { Generation }\end{array}$ & $\begin{array}{c}\text { Crossover } \\
\text { Probability }\end{array}$ & $\begin{array}{c}\text { Mutation } \\
\text { Probability }\end{array}$ & $\begin{array}{c}\text { Tournament } \\
\text { Size }\end{array}$ \\
\hline Value & 50 & 300 & 0.9 & 0.1 & 2 \\
\hline
\end{tabular}




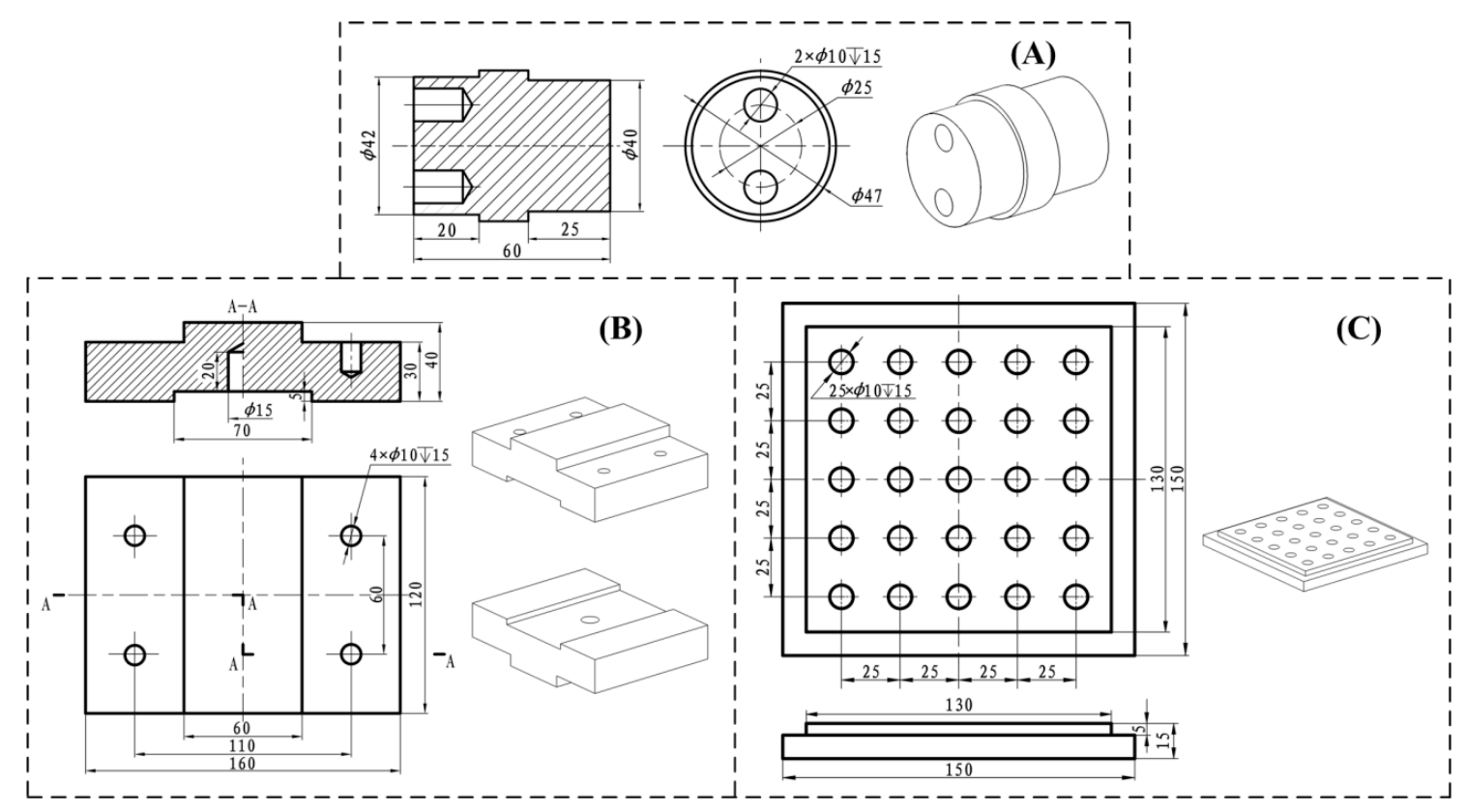

Figure 5. Three kinds of parts [37].
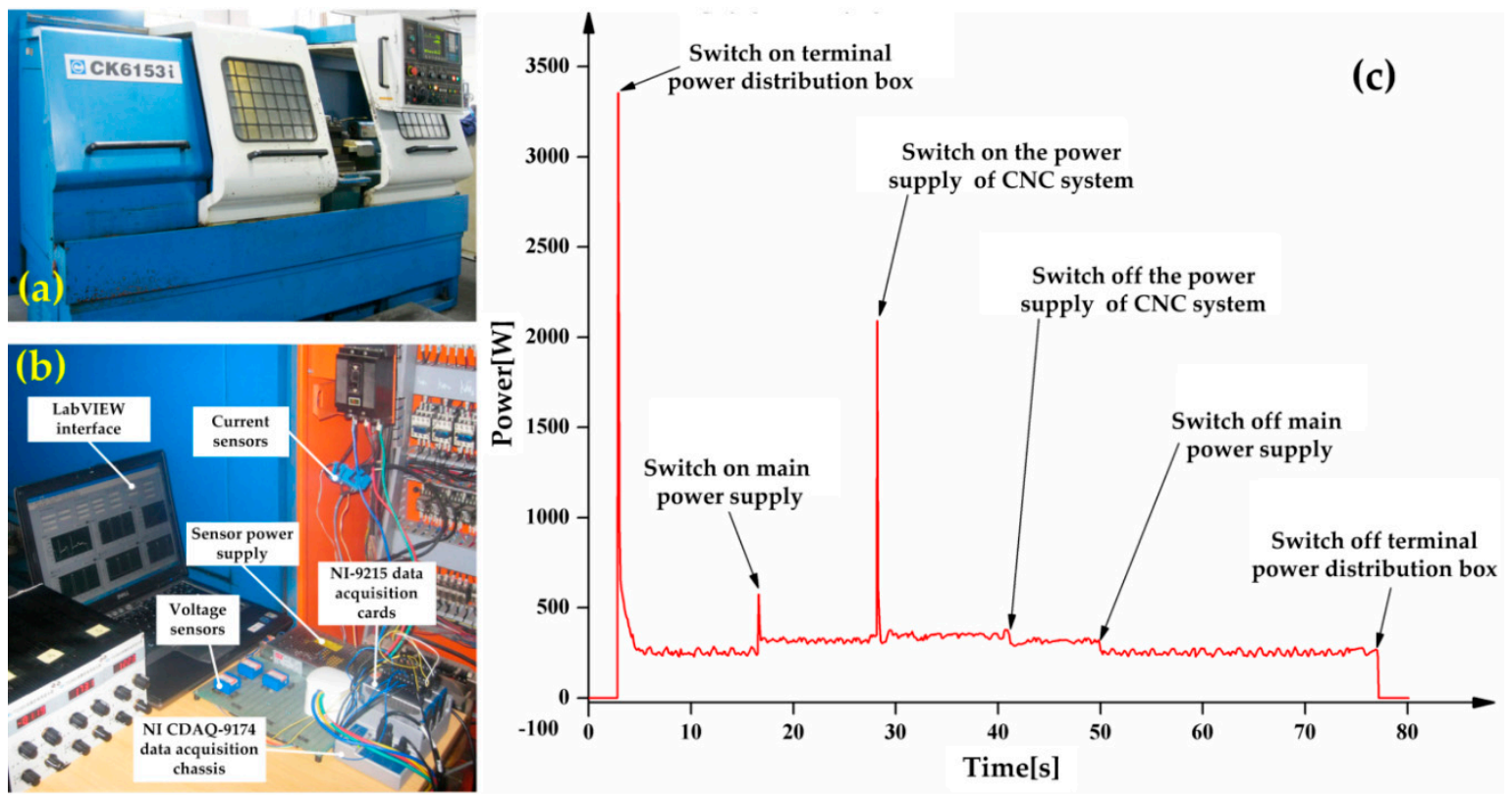

Figure 6. An example of measuring Setup operation time and EC: (a) numerical control lathe CK6153i; (b) experimental setup for EC data acquisition; (c) the power profile of Setup operation for CK6153i. 


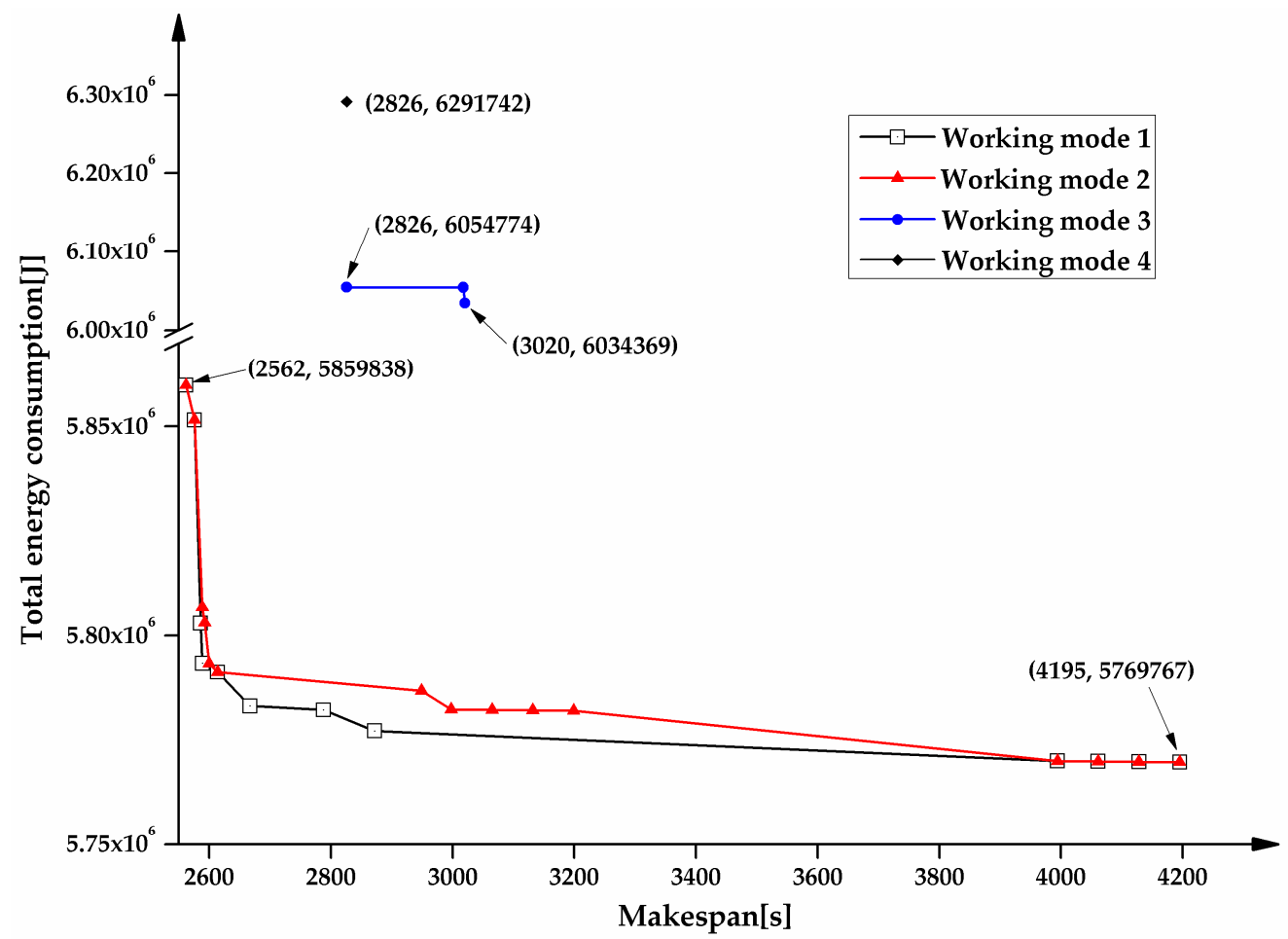

Figure 7. Solution comparison of four working modes.
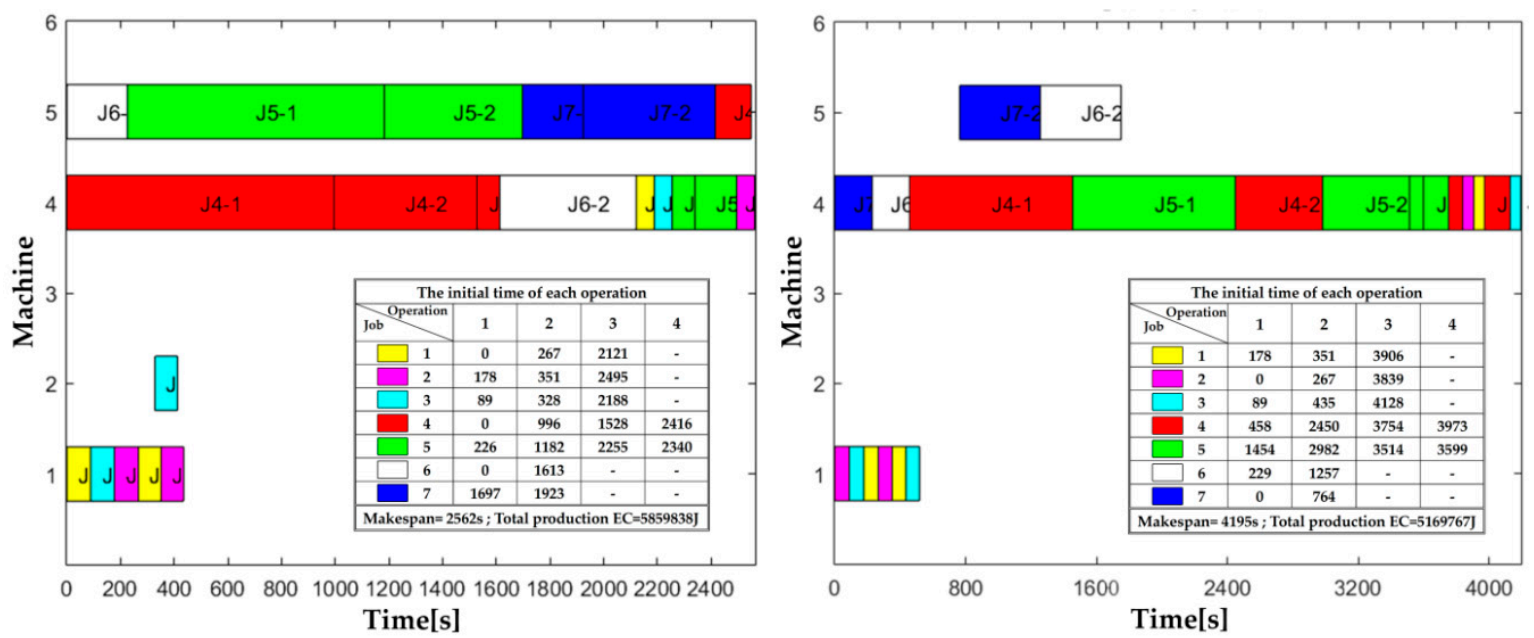

Figure 8. Schedule Gantt charts corresponding to the solutions in two boundaries of the Pareto front in working mode 1 .

As revealed by Figure 7, makespan conflicts with EC in the Pareto front in the first two working modes. When total production EC was reduced by $11.7 \%$ from $5,859,838 \mathrm{~J}$ to $5,169,797 \mathrm{~J}$, the corresponding makespan increased by $63.8 \%$ from $2562 \mathrm{~s}$ to $4195 \mathrm{~s}$. In the Pareto front, even though there was the same change of makespan, the degree of EC optimization was quite different. Hence, makespan and EC can be treated as two independent optimization objectives in a flexible job shop environment. Although there were some regions where the Pareto fronts were very close or coincide for working mode 1 and 2 , the region where the Pareto front obtained in working mode 1 outside that in working mode 2 was rather large, which means an energy-efficient mechanism further enhances the EC optimization potential on the basis of ES. According to Figure 8, the machine with higher energy efficiency tended to be selected for an operation when much more attention was paid to EC than makespan. However, the processing time of Part B was far longer than that of the other two kinds of parts, so the completion time of Part B determined makespan to a large extent. Owing to the small scale of example, the overall solution space was relatively limited 
and the optimal solution found in working mode 4 was unique. The solution comparison of working mode 3 and 4 showed that total production EC could be further reduced by employing the energy-efficient mechanism despite the same makespan (2826 s), which was consistent with the research conclusions in [22]. Meanwhile, the solution comparison between working mode 1 and 3 demonstrated that the flexibility of machine selection can improve energy-saving potential obviously.

\subsection{Experiment 2}

This experiment was carried out from two aspects to evaluate the performance of the NSGA-II applied in our study by comparing the solutions obtained with other intelligent algorithms. Firstly, the example in Experiment 1 corresponding to the first working mode was solved with ACO used in [38]. Furthermore, By reviewing the existing literature related to EFJSS, the example including four jobs and seven machines in [39] was selected, and the performance comparison was made between the algorithms used in [39], namely modified genetic algorithm (MGA) and GA-PSO, and the NSGA-II we used.

As a typical stochastic intelligent search algorithm, ACO is inspired by the behavior of ants searching the shortest path during foraging. For a specific FJSS example, the number of total operations is fixed, and each operation can be regarded as a node through which ants crawl. In each node, the probability of a machine to be selected is affected by pheromone level and heuristic information. Correspondingly, each ant constructs a solution to the scheduling problem by traveling all nodes. Note that the precedence relationship of operations belonging to the same job results in the order of ants passing through these nodes cannot be violated. The general idea of ACO in [38] was applying different pheromone trail matrices for different optimization objectives. The iteration number, the number of ants, the pheromone exponential weight, the heuristic exponential weight, and the pheromone evaporation rate were assigned 300, 50, 2, 3 and 0.01 respectively in this ACO. For more details, such as the probability distribution for node selection and the pheromone evaporation rule, can refer to [38]. Since the crawling path of each ant represents a solution to the problem, the operation-based encoding scheme, the decoding scheme as well as the non-dominated sorting in this paper can all be used for reference. In each iteration, only the ants in the non-dominated front were allowed to update both pheromone matrices. Correspondingly, the non-dominated front gradually moved outward with the iteration of ACO, and the final non-dominated front was viewed as the Pareto front. With the same computer and programming language, the Pareto front obtained by ACO was highly close to that obtained by NSGA-II. However, the mean searching time of ACO was much longer ( $82 \mathrm{~s}$ versus $31 \mathrm{~s}$ ). Thus, the NSGA-II used in our study is feasible to solve EFJSS model.

For the example in [39], transportation time was neglected and the energy-efficient mechanism was not adopted. Total production cost, including processing cost and idle cost, and total production EC were two independent optimization objectives, and a two-stage solution method was proposed. From the viewpoint of EC, the first stage only paid attention to reducing total processing EC, and an MGA was utilized to choose an appropriate machine for each operation; After that, total idle EC was focused, and a method integrating GA with PSO, namely GA-PSO, was adopted to enable operation sequencing for reducing it at the second stage. The basic machining information of jobs is shown by Table 6 . Further, the NSGA-II in our study with the basic running parameters set as Table 5 was utilized to solve this example, and the solution comparison was carried out from three aspects. 
Table 6. Machining time, processing cost and EC of each operation [39].

\begin{tabular}{|c|c|c|c|c|c|c|c|c|}
\hline \multirow{2}{*}{ Job } & \multirow{2}{*}{ Operation } & \multicolumn{7}{|c|}{ Machine Tool (min, RMB, kJ) } \\
\hline & & 1 & 2 & 3 & 4 & 5 & 6 & 7 \\
\hline \multirow{5}{*}{1} & 1 & $(2.0,2.04,720)$ & $(1.0,1.22,492)$ & - & - & - & - & - \\
\hline & 2 & - & - & $(2.0,2.78,621)$ & $(2.0,3.21,756)$ & - & - & - \\
\hline & 3 & - & - & - & - & - & $(1.5,1.46,432)$ & - \\
\hline & 4 & - & - & - & & $(1.0,1.55,342)$ & - & - \\
\hline & 5 & - & - & - & - & - & - & $(2.0,2.08,636)$ \\
\hline \multirow{5}{*}{2} & 1 & $(2.0,2.04,696)$ & $(2.0,2.44,960)$ & - & - & - & - & - \\
\hline & 2 & - & - & - & - & $(1.0,1.55,348)$ & - & - \\
\hline & 3 & - & - & - & - & - & $(1.0,0.97,270)$ & - \\
\hline & 4 & - & - & $(2.0,2.78,600)$ & $(1.0,1.61,426)$ & - & - & - \\
\hline & 5 & - & - & - & - & - & - & $(2.0,2.08,576)$ \\
\hline \multirow{5}{*}{3} & 1 & - & - & - & - & $(1.0,1.55,324)$ & - & - \\
\hline & 2 & $(2.0,2.04,744)$ & $(2.0,2.44,996)$ & - & - & - & - & - \\
\hline & 3 & - & - & - & - & - & - & $(2.0,2.08,540)$ \\
\hline & 4 & - & - & $(2.0,2.78,564)$ & $(1.0,1.61,432)$ & - & - & - \\
\hline & 5 & - & - & - & - & - & $(1.5,1.46,387)$ & - \\
\hline \multirow{5}{*}{4} & 1 & - & - & $(2.0,2.78,684)$ & $(1.0,1.61,438)$ & - & - & - \\
\hline & 2 & $(2.0,2.04,732)$ & $(2.0,2.44,996)$ & - & - & - & - & - \\
\hline & 3 & - & - & - & - & $(1.0,1.61,330)$ & - & - \\
\hline & 4 & - & - & - & - & - & - & $(2.0,2.08,600)$ \\
\hline & 5 & - & - & - & - & - & $(1.5,1.46,378)$ & - \\
\hline
\end{tabular}


Firstly, take machining EC and processing cost as the optimization objectives to make the comparison, which was corresponding to the first optimization stage for machine selection. Owing to the relatively small scale of example, the optimal solution obtained by NSGA-II was unique, i.e., the minimum total processing EC was $0.9744 \times 10^{4} \mathrm{~kJ}$ and the minimum total processing cost was 34.88RMB. However, since makespan was not considered as the optimization goal, the scheduling scheme corresponding to the optimal solution was not unique, as is shown by Figure 9. Moreover, as the weighted sum method in which the weight value of each objective was designed by a decision-maker was used for transforming the MOP to a SOP, the solution obtained with MGA was a little different from ours in that Machine 1 was superior to Machine 2 for Operation 2, and Machine 4 was more suitable than Machine 3 for Operation 4. Thus only Machines 1, 4, 5, 6 and 7 were employed to processing all operations. Accordingly, the minimum processing EC was $1.0107 \times 10^{4} \mathrm{~kJ}$ and the minimum processing cost was 36.13RMB. Obviously, the solution obtained with NSGA-II was better. Furthermore, according to Figure 9, Machines 2 and 3 were generally used only once respectively after optimization. For the machines with the same processing capability, the lower the unit processing cost and the processing power were, the greater the probability of being selected. So the optimization results obtained by MGA could be acceptable.
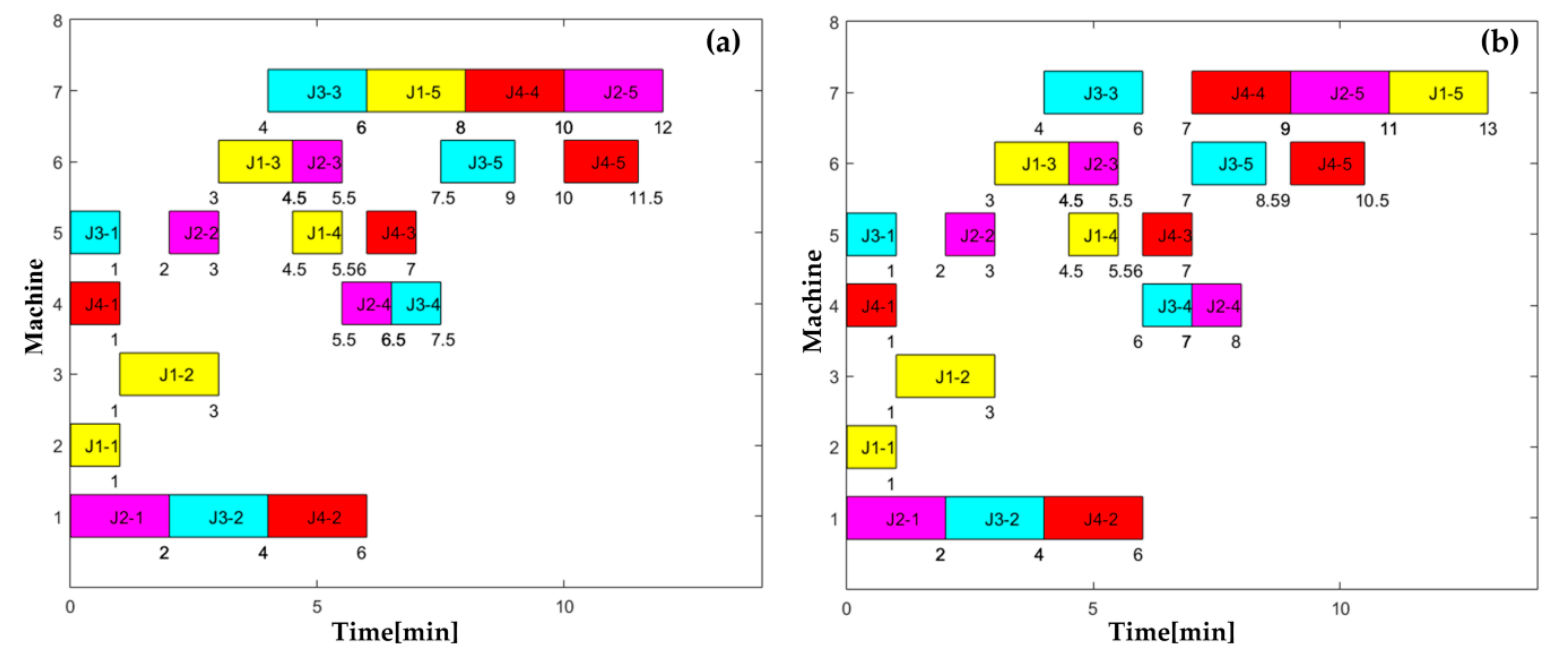

Figure 9. Schedule Gantt charts with the same machining EC and processing cost: (a) makespan = $12 \mathrm{~min}$; (b) makespan = $13 \mathrm{~min}$.

Furthermore, total idle EC and cost were chosen as the performance criteria for comparison, which was corresponding to the second optimization stage. On this condition, the example was reduced to a JSS problem after machine selection was determined. In view of stable standby state, the mean idle cost and power can be treated as constants for a machine, so the reduction of idle time can further improve the comprehensive performance of the workshop. Five machines selected at the first stage, i.e., Machines 1, 4, 5, 6 and 7, were renumbered as Machines 1-5, and the idle power of them was $3.8 \mathrm{~kW}, 4.5 \mathrm{~kW}, 4.0 \mathrm{~kW}, 2.9 \mathrm{~kW}$ and $3.0 \mathrm{~kW}$ respectively. Unfortunately, the unit idle cost of each machine was not clearly presented in such example, which affected the evaluation of total idle cost. For the sake of objectivity, the result comparison only focused on total idle EC, and the unit idle cost was assumed to be one third of the unit processing cost for each machine based on our experience. Consequently, an only optimal solution was obtained by NSGA-II, while the minimum total idle EC was $0.4533 \times 10^{4} \mathrm{~kJ}$, far less than that obtained by GA-PSO. Correspondingly, the Gantt chart of a feasible scheduling scheme with the minimum idle EC is shown by Figure 10. It is apparent that total idle time and EC can be various even with the same makespan through comparing Figures $9 \mathrm{~b}$ and 10. 


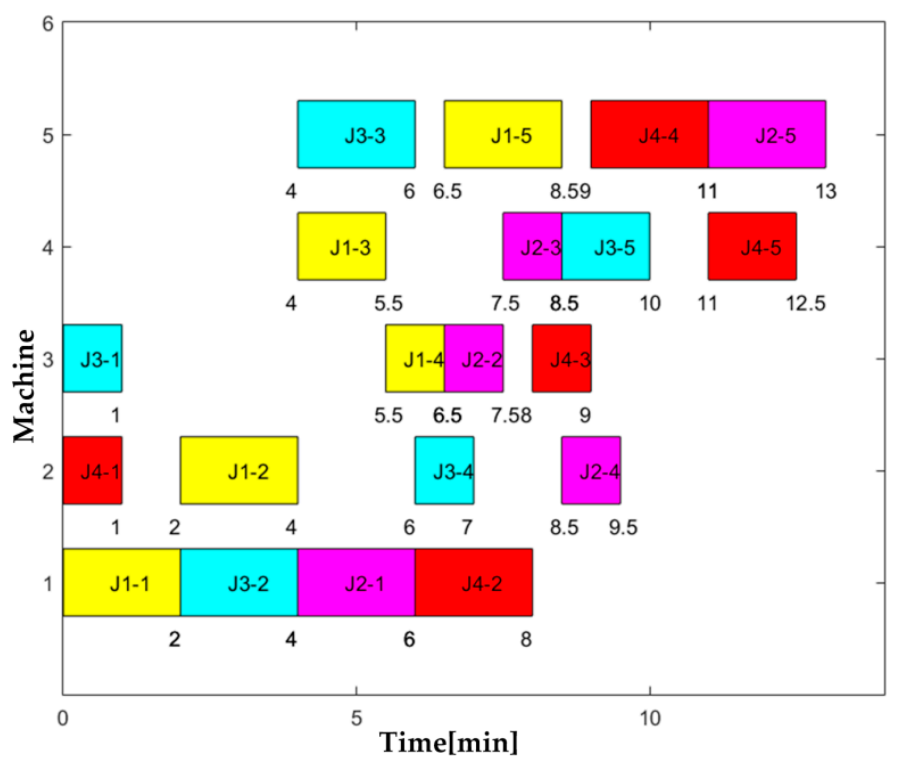

Figure 10. Schedule Gantt chart with the minimum total idle EC (makespan = $13 \mathrm{~min}$ ).

In addition, the comparison was made for the initial FJSS problem with total production EC and cost as optimization objectives. To calculate total production cost, the aforementioned unit idle cost assumption was still adopted. The optimal solution obtained by NSGA-II was still unique, and the minimum total production EC was $1.215 \times 10^{4} \mathrm{~kJ}$. The corresponding scheduling scheme is shown by Figure 11. Obviously, the total production EC after optimization from a global perspective was lower than that obtained by optimizing from two stages (i.e., $1.464 \times 10^{4} \mathrm{~kJ}$ ), which indicates that local optimum cannot guarantee global optimum. Moreover, Machine 3 was not selected, as shown in Figure 11, which also demonstrated the results of machine selection at the first optimization stage was reasonable to some extent. Besides, when changing makespan for total production cost as the optimization objective, the optimal result remained unchanged.

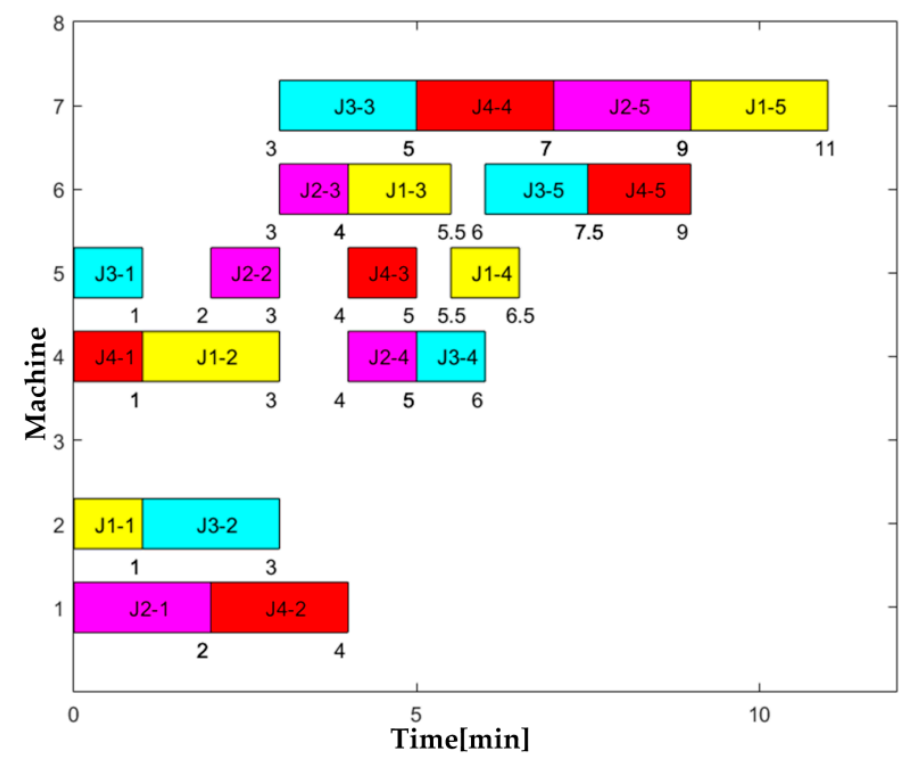

Figure 11. Schedule Gantt chart with the minimum total production EC (makespan = $11 \mathrm{~min})$.

\subsection{Discussion}

The above two experiments indicate that ES is feasible for flexible job shops to reduce EC, and EC can be viewed as an optimization objective independent of traditional scheduling indicators, 
e.g., makespan and cost. When applying the proposed scheduling approach for a flexible job shop, total processing EC and total idle EC of machines are taken into consideration as a whole. Correspondingly, machine selection and operation sequencing are carried out simultaneously, which is superior to optimization in two stages for some examples. Note that the consideration of transportation time also makes the evaluation of total production EC more reliable. Besides, no matter whether in EJSS or EFJSS, the application of an energy-efficient mechanism can enhance energy-saving potential by further optimizing total idle EC. Moreover, the NSGA-II used for solving our established EFJSS model avoids the subjective impact on different optimization objectives, and it can get better results than some other intelligent algorithms. Therefore, it can also be referred to by other FJSS studies.

\section{Conclusions}

Due to significant flexibility in alternative machines and operation sequencing in flexible job shops, it is a great challenge to reduce total production EC as well as maintain good performance for traditional scheduling objectives. Against this background, an improved scheduling approach integrating an energy-efficient mechanism was presented, and the corresponding model involving a general mixed integer programming model, which addresses productivity (i.e., makespan) and total production EC simultaneously, was established. Furthermore, an approach based on NSGA-II was applied to solve it and experiments were conducted to illustrate the effectiveness of the proposed scheduling method as well as the model solving method. The following are the main conclusions drawn from the presented research: (1) ES is also feasible for saving energy in flexible job shops from a manufacturing system-level perspective; (2) the introduction of an energy-efficient mechanism can further improve the optimization potential on the basis of ES for flexible job shops; (3) the NSGA-II used in our study can optimize machine selection and operation sequencing simultaneously, and avoid subjective effects. From a deeper perspective, if the presented scheduling approach is applied in practice, the lean production, digital and information management technology and tools will become essential and indispensable, which will enhance the overall operation and management level of workshops to some extent.

Despite the advantages of the proposed improved scheduling method, some limitations encountered in the research process need to be addressed. The actual production environment is complicated, and there are many factors affecting the prediction and measurement of EC. Although the consideration of transportation time and the application of the Therblig-based energy supply models of machines can help make the evaluation of total production EC more accurate and the scheduling schemes more practicable, this is not enough. Moreover, the necessary auxiliary time and Setup operation time are closely related to the processing equipments, tooling system, and the skills and operating methods of workers. The current study has already demonstrated the activities of operators have a significant impact on the processing EC and the Setup EC when the hardware of MS does not change dramatically, and more energy-saving potential can be discovered through better human-machine interaction and more reasonable guidance for action procedures [40]. Thus future study will focus on: (1) some other energy-consuming resources in MS except for machines; (2) the influence of human activities on the manufacturing EC; (3) an algorithm test. The NSGA-II used in our study needs testing on more complex flexible job shop scenarios to guarantee its general applicability.

Author Contributions: Z.Z. and T.P. proposed the paper structure and drafted the manuscript; L.W. programmed the algorithm; S.J. conducted the experiments and made data analysis.

Funding: This research was supported by the National Natural Science Foundation of China (No. 51175464, U1704156), the Key Science and Technology Program of Henan Province (No. 182102210391), the Foundation of the Education Department of Henan Province (No. 18A460013), the Fundamental Research Funds for the Henan Provincial Colleges and Universities in Henan University of Technology (No. 2016QNJH09), and the Foundation of Henan University of Technology (No. 2017BS014).

Acknowledgments: The authors sincerely thank editors and all anonymous reviewers for their beneficial suggestions to improve the quality of this article.

Conflicts of Interest: The authors declare no conflict of interest. 


\section{Nomenclature}

ACO Ant Colony Optimization

$A S_{i j} \quad$ The allowable earliest starting time of $O_{i j}$

$C_{i j} \quad$ The completion time of $O_{i j}$

$C_{i j}^{l k}$

$E_{k}^{\text {Setup }}$

The completion time of $O_{i j}$ which is the $l$ th operation performed on machine $k$ [s]

EC The Setup operation energy consumption of machine $k[J]$

EFJSS Energy-efficient flexible job shop scheduling

$E I_{k} \quad$ The total idle energy consumption of machine $k[\mathrm{~J}]$

$E I_{k}^{l} \quad$ The EC of idle period after the $l$ th operation performed on machine $k[J]$

EJSS Energy-efficient job shop scheduling

$E M_{k} \quad$ The total processing energy consumption of machine $k$ [J]

ES Energy-efficient scheduling

ESetup The Setup operation EC for a machine [J]

$E_{\text {total }} \quad$ The total energy consumption of machines related with all jobs [J]

FSS Flow shop scheduling

FFSS Flexible flow shop scheduling

FJSS Flexible job shop scheduling

GA Genetic algorithm

$H \quad$ An arbitrary large positive number

$i, i^{\prime}, i^{*} \quad$ Indices of jobs

$J_{i} \quad$ The number of operations to be performed for job $i$

JSS Job shop scheduling

$k, q \quad$ Indices of machines

$l, j, j^{\prime}, j^{*} \quad$ Indices of operations

$m$ The number of machines

$M E_{i j k} \quad$ The processing energy consumption of $O_{i j}$ performed on machine $k[\mathrm{~J}]$

MGA Modified genetic algorithm

MOP Multi-objective optimization problem

MS Machining system

$n \quad$ The number of jobs

NC Numerical control

$N_{k} \quad$ The set of operations that can be processed on machine $k$

NSGA-II Non-dominated sorting genetic algorithm-II

$O_{i j} \quad$ The $j$ th operation of job $i$

PMS Parallel machine scheduling

$P^{\mathrm{SO}} \quad$ The power of Therblig Standby Operation (SO) [W]

$P_{k}^{\mathrm{SO}} \quad$ The Therblig-SO power of machine $k[\mathrm{~W}]$

PSO Particle swarm optimization

$R_{k} \quad$ The actual number of operations performed on machine $k$

SA Simulated annealing

$S_{i j}^{l k} \quad$ The starting time of $O_{i j}$ which is the $l$ th operation performed on machine $k$ [s]

$S_{i j} \quad$ The starting time of $O_{i j}$

SMS Single machine scheduling

SOP Single-objective optimization problem

$T_{\mathrm{B}} \quad$ The break-event duration for a machine

$T_{\text {idle }} \quad$ The idle time between operations for a machine

$T_{k}^{\text {Setup }}$

$T_{\text {makespan }}$

The Setup operation time of machine $k[\mathrm{~J}]$

$T P_{i j k} \quad$ The processing time of $O_{i j}$ on machine $k[\mathrm{~s}]$

$T_{R} T_{k q} \quad$ The transportation time from machine $q$ to machine $k$

$T_{\text {Setup }} \quad$ The Setup operation time of a machine

$X_{i j k} \quad$ Integer decision variable with value 1 if $O_{i j}$ is processed on machine $k$, and 0 otherwise

$Y_{i j i^{*} j^{*} k} \quad$ Integer decision variable with value 1 if $O_{i j}$ precedes $O_{i^{*} j^{*}}$ when they are both processed on machine $k$, and 0 otherwise. 


\section{References}

1. Energy Statistics Division of National Bureau of Statistics. China Energy Statistical Yearbook 2014; China Statistics Press: Beijing, China, 2015.

2. Energy Information Administration (EIA). International Energy Outlook 2016. 2016. Available online: http:/ / www.eia.gov/forecasts/ieo/pdf/0484(2016).pdf (accessed on 9 May 2018).

3. Hassan Khattak, S.; Oates, M.; Greenough, R. Towards Improved Energy and Resource Management in Manufacturing. Energies 2018, 11, 1006. [CrossRef]

4. Pusavec, F.; Kramar, D.; Krajnik, P.; Kopac, J. Transitioning to sustainable production-part II: Evaluation of sustainable machining technologies. J. Clean. Prod. 2010, 18, 1211-1221. [CrossRef]

5. Peng, T.; Xu, X. Energy-efficient machining systems: A critical review. Int. J. Adv. Manuf. Technol. 2014, 72, 1389-1406. [CrossRef]

6. Dahmus, J.B.; Gutowski, T.G. An environmental analysis of machining. In Proceedings of the 2004 ASME International Mechanical Engineering Congress and Exposition, Anaheim, CA, USA, 13-19 November 2004; pp. 643-652.

7. Gutowski, T.; Murphy, C.; Allen, D.; Bauer, D.; Bras, B.; Piwonka, T.; Sheng, P.; Sutherland, J.; Thurston, D.; Wolff, E. Environmentally benign manufacturing: Observations from Japan, Europe and the United States. J. Clean. Prod. 2005, 13, 1-17. [CrossRef]

8. Blazewicz, J.; Ecker, K.H.; Pesch, E.; Schmidt, G.; Weglarz, J. Handbook on Scheduling: From Theory to Applications; Springer: Berlin, Germany, 2007.

9. Zhang, Q.; Manier, H.; Manier, M.A. A genetic algorithm with tabu search procedure for flexible job shop scheduling with transportation constraints and bounded processing times. Comput. Oper. Res. 2012, 39, 1713-1723. [CrossRef]

10. Zhao, N.; Li, K.; Tian, Q.; Du, Y. Fast optimization approach of flexible job shop scheduling with transport time consideration. Comput. Integr. Manuf. Syst. 2015, 21, 724-732. (In Chinese)

11. He, Y.; Li, Y.; Wu, T.; Sutherland, J.W. An energy-responsive optimization method for machine tool selection and operation sequence in flexible machining job shops. J. Clean. Prod. 2015, 87, 245-254. [CrossRef]

12. Mouzon, G.; Yildirim, M.B.; Twomey, J. Operational methods for minimization of energy consumption of manufacturing equipment. Int. J. Prod. Res. 2007, 45, 4247-4271. [CrossRef]

13. Liu, C.; Yang, J.; Lian, J.; Li, W.; Evans, S.; Yin, Y. Sustainable performance oriented operational decision-making of single machine systems with deterministic product arrival time. J. Clean. Prod. 2014, 85, 318-330. [CrossRef]

14. Shrouf, F.; Ordieres-Meré, J.; García-Sánchez, A.; Ortega-Mier, M. Optimizing the production scheduling of a single machine to minimize total energy consumption costs. J. Clean. Prod. 2014, 67, 197-207. [CrossRef]

15. Fang, K.-T.; Lin, B.M.T. Parallel-machine scheduling to minimize tardiness penalty and power cost. Comput. Ind. Eng. 2013, 64, 224-234. [CrossRef]

16. Wang, Y.-C.; Wang, M.-J.; Lin, S.-C. Selection of cutting conditions for power constrained parallel machine scheduling. Robot. Comput. Integr. Manuf. 2017, 43, 105-110. [CrossRef]

17. Fang, K.; Uhan, N.; Zhao, F.; Sutherland, J.W. A new approach to scheduling in manufacturing for power consumption and carbon footprint reduction. J. Manuf. Syst. 2011, 30, 234-240. [CrossRef]

18. Luo, H.; Du, B.; Huang, G.Q.; Chen, H.; Li, X. Hybrid flow shop scheduling considering machine electricity consumption cost. Int. J. Prod. Econ. 2013, 146, 423-439. [CrossRef]

19. Bruzzone, A.A.G.; Anghinolfi, D.; Paolucci, M.; Tonelli, F. Energy-aware scheduling for improving manufacturing process sustainability: A mathematical model for flexible flow shops. CIRP Ann. Manuf. Technol. 2012, 61, 459-462. [CrossRef]

20. Dai, M.; Tang, D.; Giret, A.; Salido, M.A.; Li, W.D. Energy-efficient scheduling for a flexible flow shop using an improved genetic-simulated annealing algorithm. Robot. Comput. Integr. Manuf. 2013, 29, 418-429. [CrossRef]

21. Wu, X.; Shen, X.; Cui, Q. Multi-objective flexible flow shop scheduling problem considering variable processing time due to renewable energy. Sustainability 2018, 10, 841. [CrossRef]

22. Liu, Y.; Dong, H.; Lohse, N.; Petrovic, S. A multi-objective genetic algorithm for optimisation of energy consumption and shop floor production performance. Int. J. Prod. Econ. 2016, 179, 259-272. [CrossRef] 
23. He, Y.; Liu, B.; Zhang, X.; Gao, H.; Liu, X. A modeling method of task-oriented energy consumption for machining manufacturing system. J. Clean. Prod. 2012, 23, 167-174. [CrossRef]

24. Zhang, C.; Gu, P.; Jiang, P. Low-carbon scheduling and estimating for a flexible job shop based on carbon footprint and carbon efficiency of multi-job processing. Proc. Inst. Mech. Eng. Part B J. Eng. Manuf. 2015, 229, 328-342. [CrossRef]

25. Seow, Y.; Rahimifard, S. A framework for modelling energy consumption within manufacturing systems. CIRP J. Manuf. Sci. Technol. 2011, 4, 258-264. [CrossRef]

26. Wang, Q.; Liu, F.; Wang, X. Multi-objective optimization of machining parameters considering energy consumption. Int. J. Adv. Manuf. Technol. 2014, 71, 1133-1142. [CrossRef]

27. He, Y.; Liu, F.; Wu, T.; Zhong, F.P.; Peng, B. Analysis and estimation of energy consumption for numerical control machining. Proc. Inst. Mech. Eng. Part B J. Eng. Manuf. 2011, 226, 255-266. [CrossRef]

28. Jia, S.; Tang, R.; Lv, J. Therblig-based energy demand modeling methodology of machining process to support intelligent manufacturing. J. Intell. Manuf. 2014, 25, 913-931. [CrossRef]

29. Lv, J.; Tang, R.; Jia, S. Therblig-based energy supply modeling of computer numerical control machine tools. J. Clean. Prod. 2014, 65, 168-177. [CrossRef]

30. Cruz-Chávez, M.A.; Martínez-Rangel, M.G.; Cruz-Rosales, M.H. Accelerated simulated annealing algorithm applied to the flexible job shop scheduling problem. Int. Trans. Oper. Res. 2017, 24, 1119-1137. [CrossRef]

31. Nouiri, M.; Bekrar, A.; Jemai, A.; Niar, S.; Ammari, A.C. An effective and distributed particle swarm optimization algorithm for flexible job-shop scheduling problem. J. Intell. Manuf. 2018, 29, 603-615. [CrossRef]

32. Carrizosa, E.; Romero-Morales, D. Combining minsum and minmax: A goal programming approach. Oper. Res. 2001, 49, 169-174. [CrossRef]

33. Wang, X.H.; Wan, C.H.; Sun, C.C.; Xia, R.W. An optimization algorithm for multi-objective optimization problem by using envelope-dual method. Procedia Eng. 2013, 67, 457-466. [CrossRef]

34. Deb, K.; Pratap, A.; Agarwal, S.; Meyarivan, T. A fast and elitist multiobjective genetic algorithm: NSGA-II. IEEE Trans. Evol. Comput. 2002, 6, 182-197. [CrossRef]

35. Pinedo, M.L. Scheduling: Theory, Algorithms, and Systems; Springer: New York, NY, USA, 2012.

36. Shao, X.; Li, X.; Gao, L.; Zhang, C. Integration of process planning and scheduling-A modified genetic algorithm-based approach. Comput. Oper. Res. 2009, 36, 2082-2096. [CrossRef]

37. Zhang, Z.; Tang, R.; Peng, T.; Tao, L.; Jia, S. A method for minimizing the energy consumption of machining system: Integration of process planning and scheduling. J. Clean. Prod. 2016, 137, 1647-1662. [CrossRef]

38. Iredi, S.; Merkle, D.; Middendorf, M. Bi-criterion optimization with multi colony ant algorithms. In Proceedings of the International Conference on Evolutionary Multi-Criterion Optimization, Zurich, Switzerland, 7-9 March 2001; pp. 359-372.

39. Wang, H.; Jiang, Z.; Wang, Y.; Zhang, H.; Wang, Y. A two-stage optimization method for energy-saving flexible job-shop scheduling based on energy dynamic characterization. J. Clean. Prod. 2018, 188, 575-588. [CrossRef]

40. Jia, S.; Yuan, Q.; Cai, W.; Li, M.; Li, Z. Energy modeling method of machine-operator system for sustainable machining. Energy Convers. Manag. 2018, 172, 265-276. [CrossRef]

(c) 2018 by the authors. Licensee MDPI, Basel, Switzerland. This article is an open access article distributed under the terms and conditions of the Creative Commons Attribution (CC BY) license (http:/ / creativecommons.org/licenses/by/4.0/). 